\title{
Involvement of the Prelimbic-Infralimbic Areas of the Rodent Prefrontal Cortex in Behavioral Flexibility for Place and Response Learning
}

\author{
Michael E. Ragozzino, Shauna Detrick, and Raymond P. Kesner \\ Department of Psychology, University of Utah, Salt Lake City, Utah, 84112
}

The present experiments investigated the role of the prelimbicinfralimbic areas in behavioral flexibility using a place-response learning paradigm. All rats received a bilateral cannula implant aimed at the prelimbic-infralimbic areas. To examine the role of the prelimbic-infralimbic areas in shifting strategies, rats were tested on a place and a response discrimination in a crossmaze. Some rats were tested on the place version first followed by the response version. The procedure for the other rats was reversed. Infusions of $2 \%$ tetracaine into the prelimbic-infralimbic areas did not impair acquisition of the place or response discriminations. Prelimbic-infralimbic inactivation did impair learning when rats were switched from one discrimination to the other (cross-modal shift). To investigate the role of the prelimbic-infralimbic areas in intramodal shifts (reversal learn-

Mammalian species exhibit extensive behavioral flexibility in adapting to a changing environment (Kolb, 1990). One form of behavioral flexibility manifested by mammals under changing environmental conditions is the ability to learn a new strategy while inhibiting the execution of a previous strategy. This type of flexibility has received considerable attention with the investigation of cognitive functions mediated by the prefrontal cortex in humans and nonhuman primates (Milner, 1964; Owen et al., 1990, 1993; Dias et al., 1996, 1997). Recent findings in nonhuman primates indicate that different prefrontal cortex subregions are involved in different types of cognitive flexibility (Dias et al., 1996, 1997). For example, dorsolateral prefrontal cortex lesions impair cross-modal shifts, which involve inhibiting responses based on one dimension that was previously correct and learning to respond based on a different dimension. However, dorsolateral prefrontal lesions do not impair intramodal shifts (reversal learning), which involve inhibiting a response to one exemplar in a particular dimension and learning to respond to another exemplar within the same dimension (Dias et al., 1996, 1997). Conversely, orbital prefrontal cortex lesions impair intramodal shifts but do not impair cross-modal shifts (Dias et al., 1996, 1997).

Comparable with findings in primates, there is evidence that separate rodent prefrontal cortex subregions differentially contribute to varied mnemonic functions (Eichenbaum et al., 1983;

\footnotetext{
Received Jan. 19, 1999; revised March 8, 1999; accepted March 10, 1999.

This research was supported by National Institutes of Health Grant RO1NS20771 (to R.P.K) and National Institute of Mental Health Grant MH11741 (to M.E.R.). We thank Eric Newbold for valuable assistance with behavioral testing and Robert Schaffer for excellent histological work.

Correspondence should be addressed to Raymond P. Kesner, Department of Psychology, 502 Behavioral Science Building, University of Utah, Salt Lake City, UT 84112

Copyright (C) 1999 Society for Neuroscience $\quad 0270-6474 / 99 / 194585-10 \$ 05.00 / 0$
}

ing), one group of rats was tested on a place reversal and another group tested on a response reversal. Prelimbic-infralimbic inactivation did not impair place or response intramodal shifts. Some rats that completed testing on a particular version in the cross-modal and intramodal experiments were tested on the same version in a new room for $3 \mathrm{~d}$. The transfer tests revealed that rats use a spatial strategy on the place version and an egocentric response strategy on the response version. Overall, these results suggest that the prelimbic-infralimbic areas are important for behavioral flexibility involving crossmodal but not intramodal shifts.

Key words: prefrontal cortex; prelimbic; infralimbic; reversal learning; attentional set shifting; tetracaine; flexibility

Seamans et al., 1995; Kesner et al., 1996; Bussey et al., 1997; DeCoteau et al., 1997; Ragozzino et al., 1998). However, it remains unclear whether different rodent prefrontal cortex subregions are involved in different types of behavioral flexibility. Most experiments examining the role of the rat prefrontal cortex in behavioral flexibility have investigated intramodal shifts, which have yielded varied results (Jeeves, 1967; Kolb et al., 1974, 1983; Nonneman et al., 1974; Becker and Olton, 1980; Becker et al., 1981; Kesner et al., 1989; Aggleton et al., 1995; Granon and Poucet, 1995).

The equivocal results on intramodal shifts in frontal cortexlesioned rats may be attributable to differences in lesion size or placement and/or because particular prefrontal subregions are preferentially involved in intramodal shifts, whereas other subregions are involved in other forms of behavioral flexibility. To understand the neural circuitry involved in cross-modal shifts, our laboratory examined whether dorsal anterior cingulate or prelimbic-infralimbic inactivation impairs shifting between place and visual cued versions in a cheese board task (Ragozzino et al., 1999). The results indicated that prelimbic-infralimbic inactivation but not dorsal anterior cingulate impaired the shifting between the place and visual cued discriminations. These findings suggest that the prelimbic-infralimbic areas are involved in crossmodal shifts.

At present, unknown is whether the prelimbic-infralimbic areas are specifically involved in the shifting between the place and visual-cued modes or are more generally involved in cross-modal shifts. It is also unclear whether the prelimbic-infralimbic areas are involved in intramodal shifts. The present experiments examined whether prelimbic-infralimbic inactivation impairs the shifting between place and response learning as well as place or response intramodal shifts. 


\section{MATERIALS AND METHODS}

Subjects. Male Long-Evans rats (Simonsen Laboratories, Gilroy, CA) weighing between 300 and $350 \mathrm{gm}$ at the beginning of the experiment served as subjects. Rats were housed individually in stainless steel cages $(20 \mathrm{~cm}$ wide $\times 24 \mathrm{~cm}$ long $\times 20 \mathrm{~cm}$ high) located in a temperaturecontrolled room $\left(24^{\circ} \mathrm{C}\right)$ that was maintained at $20-25 \%$ humidity. Rats were kept on a $12 \mathrm{hr}$ light/dark cycle (lights on at 7 A.M.). All rats were food-restricted to maintain their weight at $85 \%$ of their ad libitum weight with free access to water throughout the experiment.

Apparatus. The cross-maze was a four-arm maze made of $0.7-\mathrm{cm}$-thick wood that was painted black. The maze was placed on a circular platform that was elevated $26 \mathrm{~cm}$ above the floor. Each arm was $50.8 \mathrm{~cm}$ long $\times 8.9$ $\mathrm{cm}$ wide, and the height of the arm walls was $16.5 \mathrm{~cm}$. Each arm contained a food well $(3.0 \mathrm{~cm}$ diameter $\times 2.5 \mathrm{~cm}$ high $)$ that was $3.2 \mathrm{~cm}$ from the end wall. Each food well hole was $2.0 \mathrm{~cm}$ in diameter and 1.25 $\mathrm{cm}$ deep. The center platform was $18 \times 18 \mathrm{~cm}$.

Surgery. Rats received atropine sulfate $(0.2 \mathrm{ml}$ of a $250 \mu \mathrm{g} / \mathrm{ml}$ solution, i.p.) $20 \mathrm{~min}$ before administering the anesthetic (sodium pentobarbital; $55 \mathrm{mg} / \mathrm{kg}$, i.p.). A midsagittal incision was made, and the scalp was retracted. Each rat received a bilateral implant of an $8 \mathrm{~mm}$ stainless steel guide cannula (22 gauge; Plastics One, Roanoke, VA) aimed toward the prelimbic-infralimbic areas. The stereotaxic coordinates were 3.0 anterior to bregma, \pm 2.0 lateral to the midline, and 3.0 ventral to dura. The cannulae were inserted at a $15^{\circ}$ angle. The coordinates were based on the atlas of Paxinos and Watson (1986). Six jeweler's screws were placed in the skull surrounding the cannulae. The cannulae were secured in place with dental acrylic (Plastics One). Stylets were secured on the guide cannulae after the dental acrylic dried. After surgery, rats received ground rat chow mixed in water for $2 \mathrm{~d}$. To prevent infection, rats' water was replaced with a $0.6 \%$ terramyacin solution for 1 week.

Microinfusion. Injections into the prelimbic-infralimbic areas were made through an inner cannula ( 28 gauge) that extended $1.0 \mathrm{~mm}$ below the guide cannula. The inner cannula was attached by a polyethylene tube (PE-20; Becton Dickinson, Sparks, MD) to a $10 \mu$ l syringe (Hamilton, Reno, NV). The syringe was driven by a microinfusion pump (74900 series; Cole-Parmer, Vernon Hills, IL) with solutions infused in a volume of $0.5 \mu \mathrm{l} / 2 \mathrm{~min}$. The inner cannula was left in place for $1 \mathrm{~min}$ after the infusion was complete to allow for diffusion. Rats received either $2 \%$ tetracaine hydrochloride (Sigma, St. Louis, MO) or the vehicle solution, sterile saline as described below. Tetracaine hydrochloride is a local anesthetic that acts principally by blocking sodium channels (Velly et al., 1988; Thomsen et al., 1993). A 2\% tetracaine solution was used based on previous behavioral experiments using this concentration, in which intracranial injections were found to alter neuronal activity for 15-20 min (Mizumori et al., 1989, 1990).

Habituation procedure. Two days after surgery rats were foodrestricted to $85 \%$ of their ad libitum weight. During food restriction, rats were also handled for $10 \mathrm{~min} / \mathrm{d}$. Five days after food restriction and handling, the habituation phase was started. On the first day of habituation, three pieces of Froot Loops (Kellogg, Battle Creek, MI) were placed in each arm, two pieces in the food well and one piece outside the food well. A rat was placed in the maze and allowed to freely navigate and consume cereal pieces for $12 \mathrm{~min}$. On the second habituation day the procedure was the same, except that after a rat consumed two cereal pieces, the rat was picked up and placed in a different arm. This acclimated the rat to being handled in the maze after consuming cereal. On the third habituation day, the procedure was the same as day 2, except that there were only two cereal pieces put in each food well for a total of eight cereal pieces. Immediately after consuming the cereal on day 3 , the turn bias for a rat was determined. For assessing the turn bias the maze was made into a T maze by placing a wood block $(9 \mathrm{~cm}$ wide $\times 13 \mathrm{~cm}$ high $\times 1.25 \mathrm{~cm}$ thick) painted black such that it prevented entry into one arm. No cereal was placed in the food wells during this procedure. The rat was placed in the "stem" arm and could turn $90^{\circ}$ left or right after reaching the middle area. After making a turn and reaching the end of an arm, the rat was placed back in its home cage that served as a holding cage. Before the beginning of the next trial the maze was wiped down with a sponge moistened with $\sim 1 \%$ didecyl dimethyl ammonium chloride solution (Spartan Chemical, Toledo, $\mathrm{OH}$ ). Each rat received a maximum of seven trials. A rat's turn bias was determined when it made four turns in one direction.

After determining the turn bias, a rat's stylets were removed from the guide cannulae, and an inner cannula was inserted for $1 \mathrm{~min}$. There was no solution injected at this time. This procedure was performed to

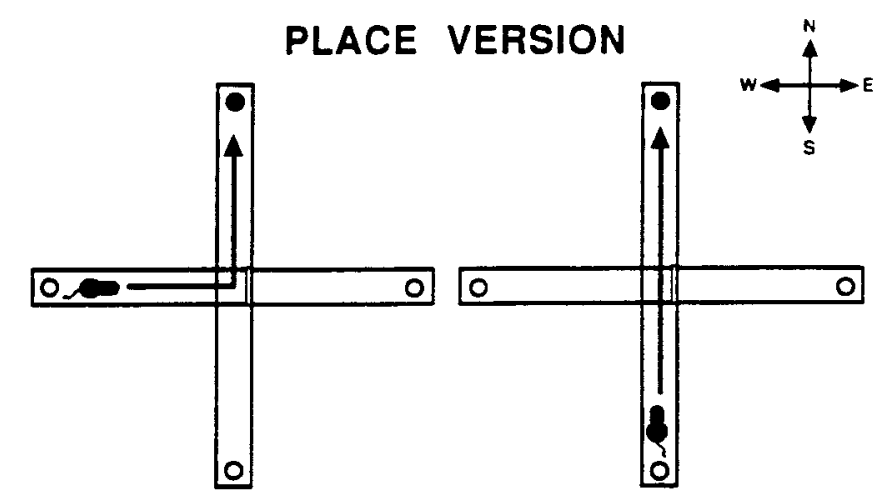

RESPONSE VERSION

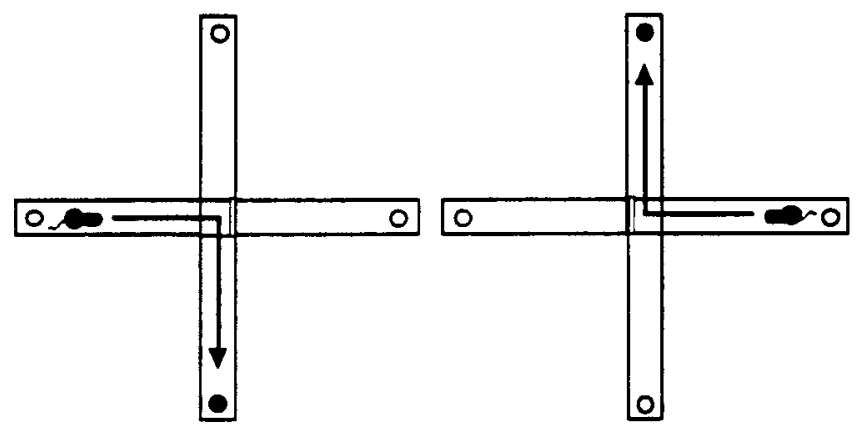

Figure 1. Example of a rat tested on the place and response discriminations. In the place version, this rat was started from the $\mathrm{S}$ and $\mathrm{W}$ arms and always had to enter the $\mathrm{N}$ arm to receive a cereal reinforcement. In the response version, this rat was started from the $\mathrm{E}$ and $\mathrm{W}$ arms and always had to turn right to receive a cereal reinforcement. The arrows in the maze represent the correct navigation patterns to receive a reinforcement. •, Food well containing cereal reinforcement.

prevent clogging of the microinf usion on test days. Behavioral testing was started the next day.

Experiment 1: place-response testing procedure. The testing procedure was modified from that of Thompson et al. (1980). For each discrimination two start arms were used. One start arm remained the same for both discriminations, and one start arm was changed on each discrimination. This design allowed training rats on a motor response not reinforced on the first discrimination, as described in more detail below. In this experiment, each rat was started on the place version. A rat was started from two of three start arms designated E, S, and W. All rats were started from the $\mathrm{S}$ arm and either the $\mathrm{E}$ or $\mathrm{W}$ arm. A rat always had a choice between two arms to enter with the third arm blocked off. If a rat started from the $\mathrm{E}$ or $\mathrm{W}$ arm, it had a choice to make a $90^{\circ}$ turn to the left or right. If a rat started from the $\mathrm{S}$ arm, it had a choice to run straight or turn left or right, but not both. This depended on which arm the block was placed in. For example, if the block was placed in the $\mathrm{W}$ arm a rat could run straight or turn right. If the block was in the $\mathrm{E}$ arm a rat could run straight or turn left. A rat always had an option to make the same turn as its turn bias from the S start arm. From any start arm the rat had to enter the $\mathrm{N}$ arm to receive a half-piece of Froot Loops cereal. Figure 1, top, illustrates an example of the correct navigation patterns on the place discrimination for a rat that was started from the $\mathrm{S}$ and $\mathrm{W}$ arms. There were 20 trials per daily session, with half of the trials beginning from each start arm and administered in a random manner. Between trials the rat was placed back in its home cage, which was on a shelf next to the maze. Subsequently, the maze arms were wiped down with a sponge moistened with the ammonium chloride solution. The intertrial interval was $\sim 10 \mathrm{sec}$. To minimize the use of intramaze cues, every four to six trials the maze was turned $90^{\circ}$ clockwise relative to the experimenter. Once a rat made 10 correct choices consecutively, a probe trial was given. The probe trial consisted of starting the rat from the third start arm (E or W) not used during testing. If a rat correctly entered the $\mathrm{N}$ arm, then place testing was completed. If a rat did not enter the $\mathrm{N}$ arm, then place testing was continued until a rat made an additional five correct choices consecu- 
tively, at which point another probe trial was administered. This procedure was continued until a rat made a correct choice on the probe trial. In situations in which a rat missed a probe trial and $<5$ test trials were left in the 20 trial session, the rat was still tested for the few remaining trials. However, any correct choices at the end of a session did not carry over to the session the next day. The following three measures were taken for each rat: (1) acquisition criterion, defined as the total number of test trials to complete 10 consecutive correct choices in a session; (2) trials to criterion, defined as the total number of test trials completed before a correct choice on the probe trial was made; and (3) probe trials, defined as the total number of probe trials to get one correct. Based on these criteria it was possible that the scores for the acquisition criterion and trials to criterion were the same if a rat made a correct choice on the first probe trial.

The day after reaching criterion on the place version, rats were switched to the response version. In the response version the $\mathrm{E}$ and $\mathrm{W}$ arms were the two start arms for all rats. A rat always had the choice of making a $90^{\circ}$ turn left or right. A rat had to turn opposite of its turn bias to receive half of a cereal piece. Figure 1, bottom, shows an example of a rat that was conditioned to turn right in the response discrimination. All other aspects of the testing procedure were the same as in the place version. Although the same criteria to complete the response version were used as in the place version, additional measures were examined on the switch to determine whether treatments altered perseveration and/or learning. For example, if a rat was started from the $\mathrm{S}$ and $\mathrm{W}$ arms on the place version, then it was started from the $\mathrm{E}$ and $\mathrm{W}$ arms on the response version and conditioned to turn right (Fig. 1). In this situation, when started from the $\mathrm{W}$ arm on the response version, the rat had to turn away from the arm that was reinforced in the place version. A similar situation occurred for rats started from the $\mathrm{S}$ and $\mathrm{E}$ arms on the place version. For each rat, the 10 trials from the start arm used in the initial place discrimination and subsequent response discrimination, in which it had to turn opposite of the "place" arm, were separated into two blocks of five trials each. Perseveration was defined as entering the incorrect arm in four or more trials per block. This is a similar criteria used in a previous experiment measuring perseveration (Hunt and Aggleton, 1998). Learning from the same start arm was defined when a rat no longer exhibited perseveration in a block. Learning criterion was defined as the total trials, separated into five per block, to make five consecutive correct choices from the start arm used in the place and response versions after the last perseverative block. Performance from the new start arm during the switch provided another index of learning. Learning criterion from the new start arm was defined as the number of trials (five per block) to make five consecutive correct choices from the new start arm.

Three minutes before each test session rats received a microinf usion. Each rat was randomly assigned to one of three treatment groups. Group assignment was determined by which treatment was administered during each version: (1) place version-vehicle and response version-vehicle $(n=7)$; (2) place version-vehicle and response version-2\% tetracaine $(n=6)$; and (3) place version-2\% tetracaine and response versionvehicle $(n=6)$.

Experiment 2: response-place testing procedure

In this experiment rats were started on the response version first and then switched to the place version. All other aspects of the testing procedure were as described in Experiment 1. On the switch to the place version the same measures were assessed as those during the switch in Experiment 1. Each rat was randomly assigned to one of the following groups: (1) response version-vehicle and place version-vehicle $(n=6) ;(2)$ response version-vehicle and place version-2\% tetracaine $(n=6)$; and $(3)$ response version-2\% tetracaine and place version-vehicle $(n=6)$.

Experiment 3: place-place testing procedure. Experiment 3 investigated the effect of prelimbic-infralimbic inactivation on a place intramodal shift. All rats were started on the place version as described above. Each rat was started from the $\mathrm{S}$ and $\mathrm{E}$ arms or the $\mathrm{S}$ and $\mathrm{W}$ arms depending on a rat's turn bias, as described in Experiment 1. However, for this experiment a rat always had the option of entering the same two arms. For example, if a rat with a right turn bias was started from the $\mathrm{S}$ and $\mathrm{W}$ arms, it always had a choice of entering the $\mathrm{N}$ or $\mathrm{E}$ arm. After reaching criterion the place discrimination was reversed. All other aspects of testing were the same as described in Experiment 1. As in Experiments 1 and 2, perseveration and learning were assessed for the intramodal shift. Because the start arms remained the same during the intramodal shift, perseveration and learning were assessed in blocks of five consecutive trials for a session. The same criterion was used as in Experiment 1. Each rat was assigned to one of the two following groups: (1) place acquisition-vehicle and place reversal-vehicle $(n=5)$; and (2) place acquisition-vehicle and place reversal-2\% tetracaine $(n=5)$.

Experiment 4: response-response testing procedure. This experiment investigated the effect of prelimbic-infralimbic inactivation on a response intramodal shift. All rats were started from the E and W arms and trained to turn opposite of their turn bias. After reaching criterion to turn in one direction, the turn direction was reversed. All other aspects of testing were the same as described in Experiment 1. On the intramodal shift, perseveration and learning were assessed as described in Experiment 3. Each rat was assigned to one of the two following groups: (1) response acquisition-vehicle and response reversal-vehicle $(n=5)$; and (2) response acquisition-vehicle and response reversal-2\% tetracaine $(n=5)$.

Experiment 5: place-novel context testing procedure. This experiment determined whether prelimbic-infralimbic inactivation affects place discrimination learning when rats are shifted to a novel context. A subset of rats from Experiments 2 and 3 after completing testing on the place version was randomly chosen to be tested in this experiment. One day after completing place learning in the first room, each rat was tested on the place version in the same maze but in a different room for 3 consecutive days. All rats were trained to go to the $\mathrm{N}$ arm (relative to experimenter) as in the first room. Each rat was randomly started from three arms for a total of 20 trials. Because pilot data indicated that prelimbic-infralimbic inactivation did not impair performance compared with controls when two start arms were used, a third arm was used to possibly increase the level of difficulty. One group received vehicle injections before each test session $(n=6)$, and the other group received $2 \%$ tetracaine injections before each test session $(n=5)$. The group that received vehicle injections in the new room received either vehicle or $2 \%$ tetracaine infusions in the first room. The group that received tetracaine injections in the new room received vehicle injections in the first room. This procedure was used to minimize the possibility of sensitization to chronic tetracaine infusions.

Experiment 6: response-novel context testing procedure. Experiment 6 determined whether prelimbic-infralimbic inactivation affects the use of a response strategy when rats are shifted to a novel context. A subset of rats from Experiments 1 and 4 after completing response discrimination testing was randomly chosen to be tested in this experiment. One day after completing response learning in the first room, each rat was tested on the response version in the same maze but in a different room for 3 consecutive days. A rat was reinforced for turning the same direction as in the first room. Each rat was randomly started from the E, W, N, and $\mathrm{S}$ arms for a total of 20 trials. All four arms were used as start arms to better determine whether a rat was preferentially using an egocentric response strategy. One group received vehicle injections before each test session $(n=5)$, and the other group received $2 \%$ tetracaine injections before each test session $(n=7)$. The group that received vehicle injections in the new room received either vehicle or $2 \%$ tetracaine inf usions in the first room. The group that received tetracaine injections in the new room received vehicle injections in the first room.

Histology. After completion of behavioral testing, rats received a lethal dose of sodium pentobarbital followed by a $0.5 \mu$ injection of $2.5 \%$ Chicago blue stain through each guide cannula. As in previous experiments (Givens and Olton, 1990; Ragozzino et al., 1999), the stain was used to highlight the approximate spread of the intracranial injections. Rats were perfused intracardially with $0.9 \%$ saline followed by a $10 \%$ formalin solution. Brains were removed and placed in a 30\% sucroseformalin solution. The brains were frozen and cut in coronal sections (40 $\mu \mathrm{m})$ on a cryostat. The sections were mounted on slides, dried, and examined to determine the location of the cannula tips and the spread of the stain. The brain sections from some rats that received tetracaine inf usions and the brain sections from some rats that only received vehicle infusions were subsequently stained with cresyl violet to examine whether there were any structural changes in the brains after tetracaine infusions compared with those after vehicle infusions.

Statistical analysis. In all groups for Experiments 1-4 there was not a difference between acquisition criterion and trials to criterion, with the exception of one group in one experimental condition. Because of this, only the analysis on the trials to criterion is presented. The one exception is noted in Results. A separate ANOVA was done on the acquisition version and the switch version for Experiments 1 and 2. ANOVA tests were used to assess differences in perseveration and learning among the groups. Student's $t$ tests were used on the acquisition and reversal for Experiments 3 and 4. Student's $t$ tests were also used to analyze differences in perseveration and learning between the groups. ANOVA with 


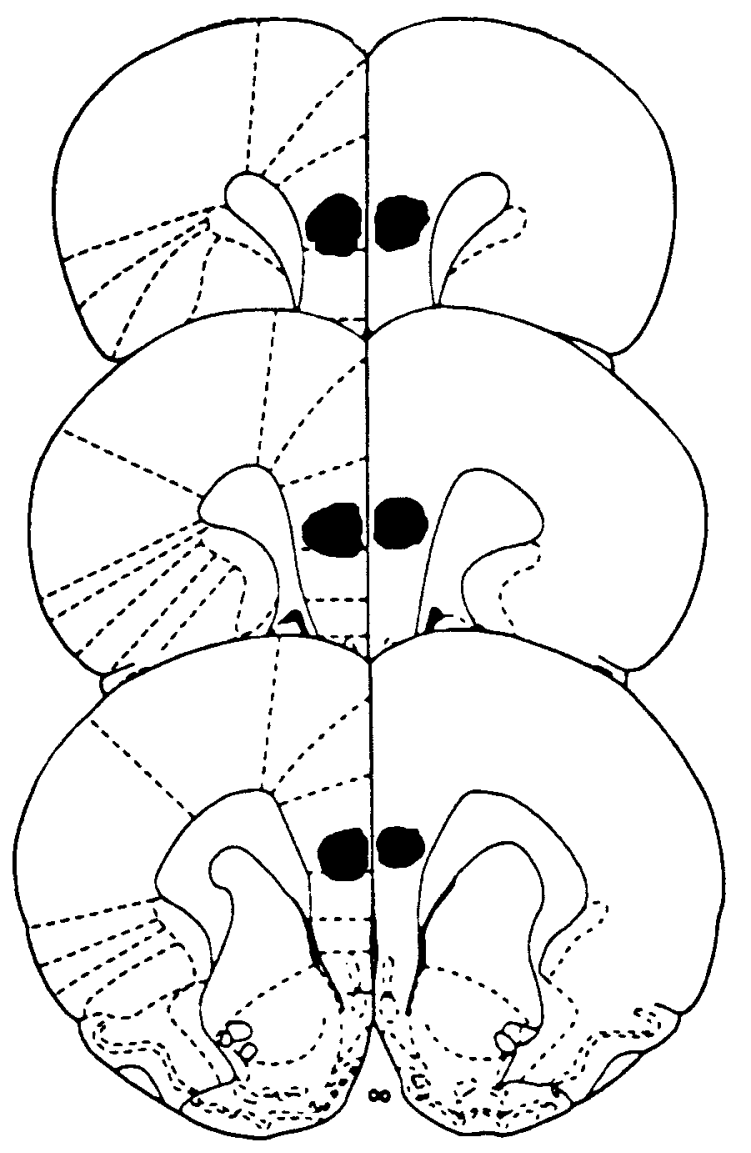

Figure 2. The black areas represent the location of the injection cannula tips in the prelimbic-infralimbic cortices for all rats included in the behavioral analyses. Rat brain sections were adapted from Paxinos and Watson (1986).

repeated measures was used to analyze the data from Experiments 5 and 6 . Table 1 shows the scores on acquisition criterion, trials to criterion, and probe trials for Experiments 1-4.

\section{RESULTS}

\section{Histology}

Figure 2 illustrates the locations of the cannula tips in the prelimbic-infralimbic areas for all of the experiments. The dye injections indicated that fluid spread ventral and lateral to the injection site and was concentrated in the prelimbic and infralimbic areas. In some cases dye diffused into the dorsomedial portion of the forceps minor corpus callosum. There was diff usion of dye dorsal to the injection site that outlined the cannula. The cannula tips were found in the central to ventral prelimbic area or dorsal infralimbic area.

Examination of the Nissl-stained sections under a light microscope did not reveal any structural differences in the prefrontal cortex sections from rats that received tetracaine infusions compared with those that received only vehicle infusions.

\section{Experiment 1: effects of prelimbic-infralimbic inactivation on acquisition of place learning and shift to response learning}

The findings on trials to criterion for place discrimination acquisition are shown in Figure $3 A$. All groups averaged $\sim 70 \%$ correct on the first test session. Their performance increased to $\sim 85 \%$ correct on the last test session. The results indicate that prelim-
A

PLACE
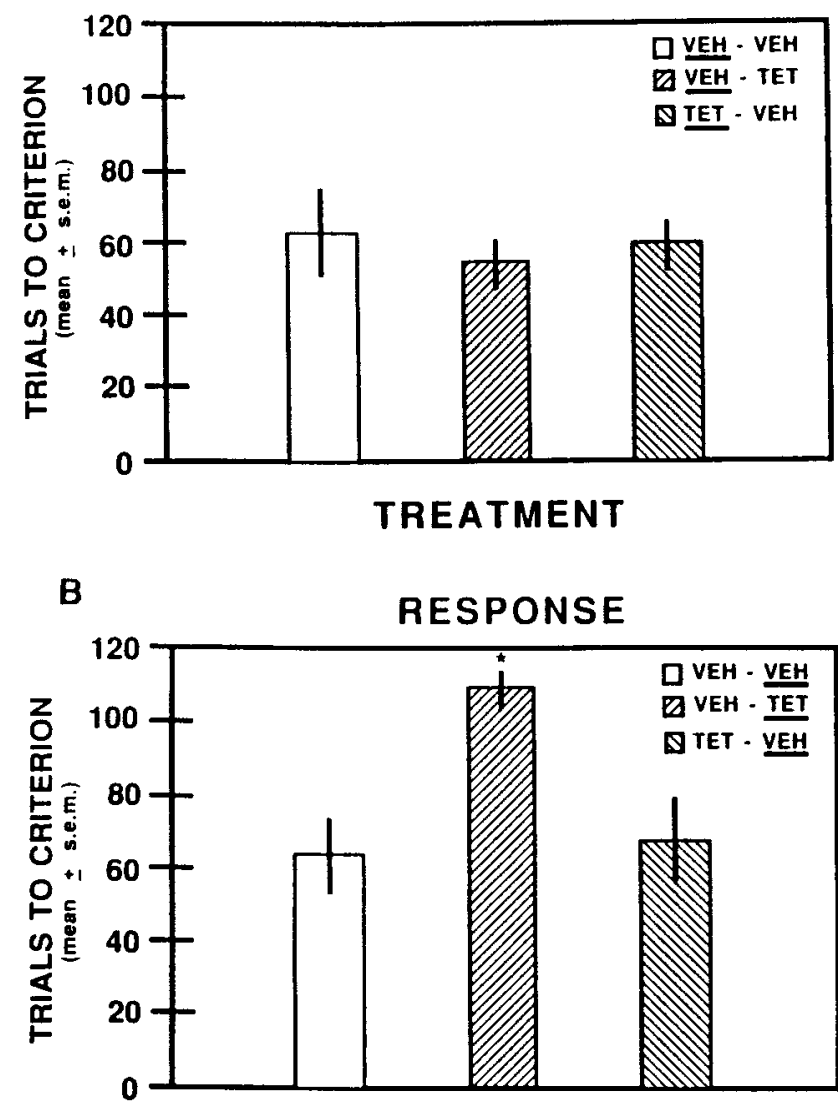

TREATMENT

C

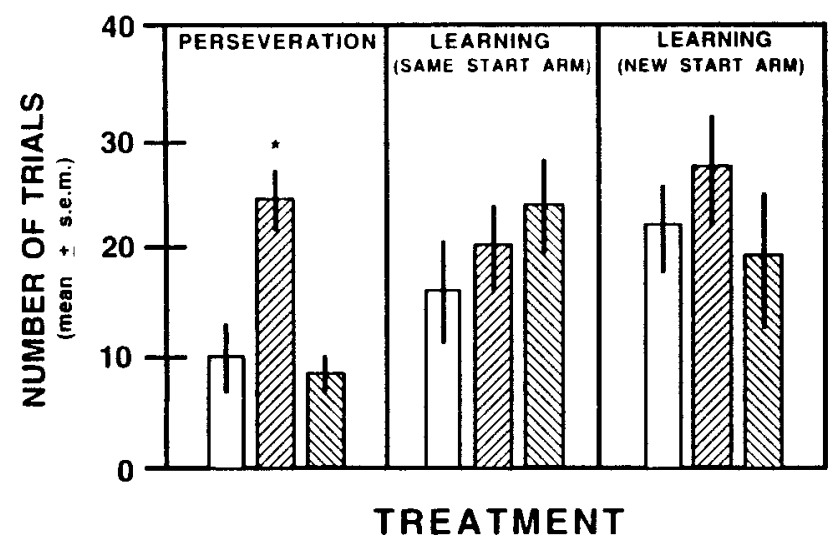

Figure 3. A, Mean trials to criterion on acquisition of the place discrimination after vehicle or $2 \%$ tetracaine infusions into the prelimbicinfralimbic areas. The treatment received on this test is underlined for each group. $V E H$, Saline; TET, $2 \%$ tetracaine. $B$, Mean trials to criterion on the shift to a response discrimination after vehicle or $2 \%$ tetracaine inf usions into the prelimbic-infralimbic areas. The treatment received on this test is underlined for each group. ${ }^{*} p<0.05$ versus vehicle-injected groups. $C$, Mean number of trials to perseverate and complete learning on the shift to a response discrimination after vehicle or $2 \%$ tetracaine injections into the prelimbic-infralimbic areas. $\square$, VEH-VEH; $\mathbb{Z}, \mathrm{VEH}-$ $\underline{T E T} ; \mathbb{\mathbb { }}$, TET-VEH. Underlined is the treatment received during the response discrimination. ${ }^{*} p<0.05$ versus vehicle-injected controls. 
Table 1. Mean number of trials \pm SEM for the three measures in Experiments 1-4 under the different testing and drug conditions

\begin{tabular}{|c|c|c|c|}
\hline & $\begin{array}{l}\text { Acquisition } \\
\text { criterion }\end{array}$ & $\begin{array}{l}\text { Trials to cri- } \\
\text { terion }\end{array}$ & $\begin{array}{l}\text { No. of } \\
\text { probe trials }\end{array}$ \\
\hline \multicolumn{4}{|l|}{ Experiment 1} \\
\hline \multicolumn{4}{|l|}{ Place version } \\
\hline Vehicle-vehicle & $57.6 \pm 12.7$ & $63.1 \pm 12.9$ & $2.0 \pm 0.7$ \\
\hline Vehicle-tetracaine & $50.3 \pm 6.6$ & $55.8 \pm 7.4$ & $1.8 \pm 0.5$ \\
\hline Tetracaine-vehicle & $38.7 \pm 4.3$ & $60.3 \pm 7.0^{*}$ & $4.8 \pm 1.4^{* *}$ \\
\hline \multicolumn{4}{|l|}{ Response version } \\
\hline Vehicle-vehicle & $64.7 \pm 11.0$ & $64.7 \pm 11.0$ & $1.0 \pm 0.0$ \\
\hline Vehicle-tetracaine & $108.3 \pm 6.2^{* *}$ & $110.8 \pm 5.1^{* *}$ & $1.3 \pm 0.3$ \\
\hline$\underline{\text { Tetracaine-vehicle }}$ & $68.5 \pm 11.6$ & $68.5 \pm 11.6$ & $1.0 \pm 0.0$ \\
\hline \multicolumn{4}{|l|}{ Experiment 2} \\
\hline \multicolumn{4}{|l|}{ Response version } \\
\hline Vehicle-vehicle & $57.5 \pm 13.6$ & $70.3 \pm 10.3$ & $2.3 \pm 0.6$ \\
\hline Vehicle-tetracaine & $68.2 \pm 10.6$ & $73.0 \pm 10.6$ & $1.8 \pm 0.5$ \\
\hline Tetracaine-vehicle & $51.0 \pm 14.7$ & $51.0 \pm 14.7$ & $1.0 \pm 0.0$ \\
\hline \multicolumn{4}{|l|}{ Place version } \\
\hline Vehicle-vehicle & $36.2 \pm 4.2$ & $37.8 \pm 4.7$ & $1.2 \pm 0.2$ \\
\hline Vehicle-tetracaine & $62.7 \pm 7.8^{* *}$ & $67.3 \pm 9.7 * *$ & $1.8 \pm 0.5$ \\
\hline Tetracaine-vehicle & $40.0 \pm 5.5$ & $44.2 \pm 3.9$ & $1.7 \pm 0.3$ \\
\hline \multicolumn{4}{|l|}{ Experiment 3} \\
\hline \multicolumn{4}{|l|}{ Place acquisition } \\
\hline Vehicle-vehicle & $56.4 \pm 12.8$ & $68.0 \pm 10.5$ & $2.2 \pm 0.7$ \\
\hline Vehicle-tetracaine & $61.2 \pm 12.0$ & $64.2 \pm 12.4$ & $1.6 \pm 0.2$ \\
\hline \multicolumn{4}{|l|}{ Place reversal } \\
\hline Vehicle-vehicle & $52.6 \pm 6.4$ & $55.6 \pm 5.6$ & $1.6 \pm 0.6$ \\
\hline Vehicle-tetracaine & $59.4 \pm 3.8$ & $69.8 \pm 8.0$ & $2.2 \pm 0.6$ \\
\hline \multicolumn{4}{|l|}{ Experiment 4} \\
\hline \multicolumn{4}{|l|}{ Response acquisition } \\
\hline$\underline{\text { Vehicle-vehicle }}$ & $68.2 \pm 13.4$ & $72.6 \pm 14.4$ & $1.6 \pm 0.2$ \\
\hline Vehicle-tetracaine & $70.0 \pm 18.5$ & $79.2 \pm 17.8$ & $1.8 \pm 0.4$ \\
\hline \multicolumn{4}{|l|}{ Response reversal } \\
\hline Vehicle-vehicle & $71.6 \pm 15.8$ & $75.6 \pm 14.9$ & $1.4 \pm 0.4$ \\
\hline Vehicle-tetracaine & $72.0 \pm 15.7$ & $73.4 \pm 16.0$ & $1.2 \pm 0.3$ \\
\hline
\end{tabular}

Underlined is the treatment administered for that condition.

$* p<0.05$ versus acquisition criterion.

${ }^{* * p}<0.05$ versus vehicle-injected controls.

bic-infralimbic inactivation did not impair acquisition of the place version. An ANOVA revealed there was no significant difference in the trials to criterion among the groups $\left(F_{(2,16)}=\right.$ $0.14 ; p>0.05)$. However, as shown in Table 1 the tetracaine group showed an increase in trials to criterion compared with acquisition criterion. To determine whether this difference was significant, a $t$ test for correlated measures was used. The analysis revealed that the difference in scores between acquisition criterion and trials to criterion was significant $\left(t_{(5)}=3.28 ; p<0.05\right)$. Furthermore, an ANOVA on the probe trials indicated that the tetracaine group had significantly more probe trials than vehicleinjected controls $\left(F_{(1,17)}=7.06 ; p<0.05\right)$.

The trials to criterion results on shifting to the response version are illustrated in Figure $3 B$. On the first session the vehiclevehicle and tetracaine-vehicle groups obtained approximately half the trials correct, with mean scores of $50.0 \pm 9.2$ (SEM) and $48.3 \pm 5.3$, respectively. The vehicle-tetracaine group exhibited lower scores, with a mean percent score of $38.7 \pm 4.3 \%$ on the first test session. All groups increased their performance to $\sim 85 \%$ correct on the final test session. The findings indicate that prelimbic-infralimbic inactivation impaired rats in switching to the response version. An ANOVA revealed that the difference in the trials to criterion among the groups was significant $\left(F_{(2,16)}=\right.$ $6.58 ; p<0.01)$. Newman-Keuls tests revealed that the tetracaine group took significantly more trials to reach criterion than either of the vehicle-injected control groups $(p<0.05)$. The difference in trials to criterion between the vehicle-injected control groups was not significant $(p>0.05)$.

Because the trials to criterion results does not reveal whether the tetracaine-induced deficit in shifting is attributable to perseveration and/or impaired learning, a further analysis was performed. Figure $3 C$ illustrates the findings on perseveration and learning for the shift to the response discrimination. The tetracaine-induced impairment on the switch reflected a perseveration of the place strategy. An ANOVA revealed that there was a significant difference in perseverative trials among the groups $\left(F_{(2,16)}=6.42 ; p<0.01\right)$. Newman-Keuls tests revealed that the tetracaine group had significantly more perseverative trials than the vehicle-injected controls $(p<0.05)$. The difference in perseverative trials between the control groups was not significant $(p>0.05)$.

The tetracaine group took a comparable amount of trials to reach learning criterion from the start arm that remained the same for the place and response versions. An ANOVA indicated that there was not a significant difference in trials to criterion among the groups $\left(F_{(2,16)}=0.77 ; p>0.05\right)$. An examination of learning from the new start arm revealed results similar to those from the same start arm. The difference in trials to criterion among the groups was not statistically significant $\left(F_{(2,16)}=0.70\right.$; $p>0.05)$. Thus, prelimbic-infralimbic inactivation did not impair learning on the shift to the response discrimination.

\section{Experiment 2: effects of prelimbic-infralimbic inactivation on acquisition of response learning and shift to place learning}

The results on acquisition of response learning are shown in Figure $4 A$. All groups averaged $\sim 50 \%$ correct on the first test session. The findings indicate that prelimbic-infralimbic inactivation did not alter acquisition of response learning. The ANOVA indicated there was not a significant difference in trials to criterion among the groups $\left(F_{(2,15)}=0.99 ; p>0.05\right)$. As shown in Table 1, the vehicle controls had more probe trials compared with those in the tetracaine group. However, even when the scores from the two control groups were collapsed and compared with those in the tetracaine group, the difference was not statistically significant $\left(F_{(1,16)}=3.97 ; p>0.05\right)$.

Figure $4 B$ illustrates the findings on switching to the place strategy. Inactivation of the prelimbic-infralimbic areas increased the trials to criterion when shifted to the place discrimination. On the first transfer session the mean percent correct for the groups was as follows: vehicle-vehicle, $67.0 \pm 1.8 \%$ (SEM); vehicle-tetracaine, $48.3 \pm 3.8 \%$; and tetracaine-vehicle, $58.3 \pm$ $4.9 \%$. An ANOVA revealed that there was a significant difference in reaching trials to criterion among the groups $\left(F_{(2,15)}=5.62\right.$; $p<0.05)$. Newman-Keuls tests indicated that the tetracaine group took significantly longer in reaching trials to criterion compared with that of vehicle-injected controls $(p<0.05)$. The difference in trials to criterion between the vehicle-injected control groups was not significant $(p>0.05)$.

As in Experiment 1, a subsequent analysis was performed to determine whether the tetracaine-induced deficit was because of perseveration and/or impaired learning. Figure $4 C$ illustrates the 
A

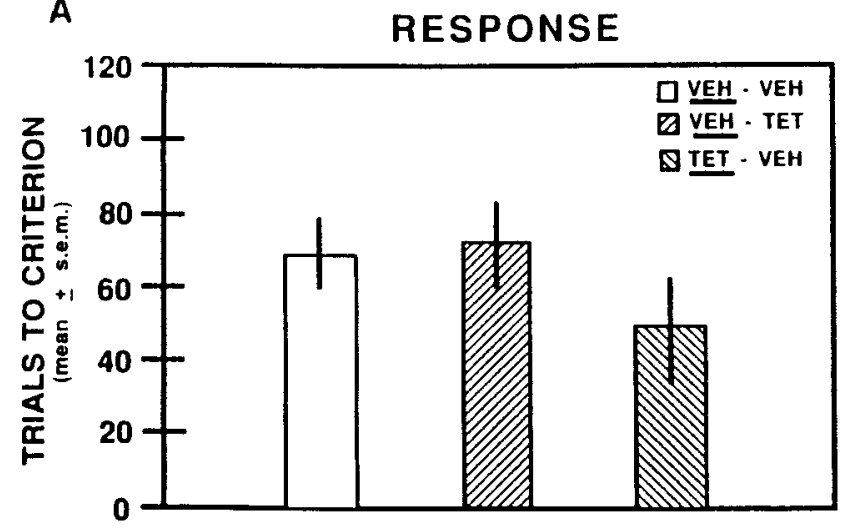

TREATMENT
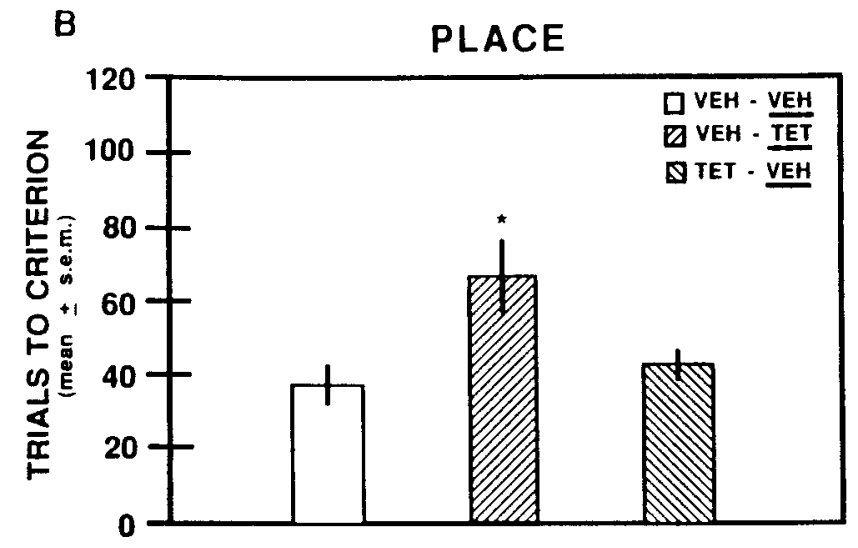

TREATMENT

\section{C}

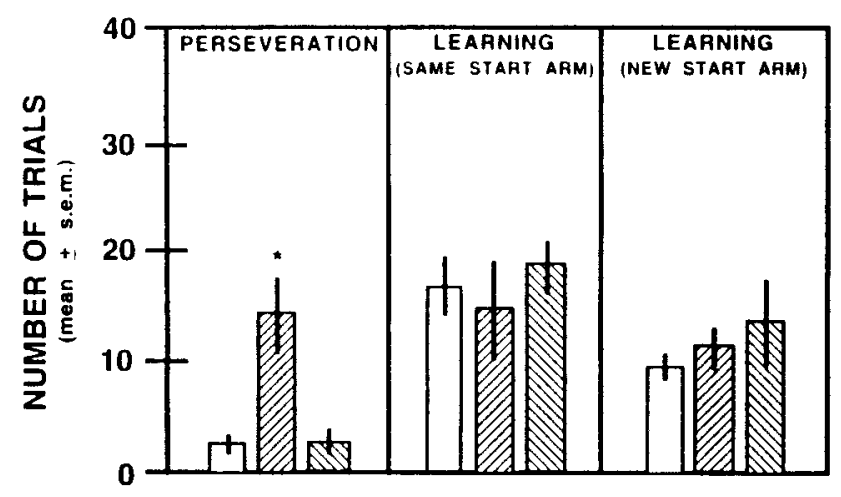

TREATMENT

Figure 4. A, Mean trials to criterion on acquisition of the response discrimination after vehicle or $2 \%$ tetracaine infusions into the prelimbic-infralimbic areas. The treatment received on this test is underlined for each group. $V E H$, Saline; TET, $2 \%$ tetracaine. $B$, Mean trials to criterion on the shift to a place discrimination after vehicle or $2 \%$ tetracaine inf usions into the prelimbic-infralimbic areas. The treatment received on this test is underlined for each group. ${ }^{*} p<0.05$ versus vehicle-injected groups. $C$, Mean number of trials to perseverate and complete learning on the shift to a place discrimination after vehicle or $2 \%$ tetracaine injections into the prelimbic-infralimbic areas. $\square, \mathrm{VEH}-\mathrm{VEH} ; \mathbb{\mathbb { Q }}, \mathrm{VEH}-\mathrm{TET} ; \mathbb{\mathbb { N }}$, TET-VEH. Underlined is the treatment received during the place discrimination. ${ }^{*} p<0.05$ versus vehicle-injected groups. results on perseveration and learning for the shift to the place discrimination. The tetracaine-injected group on the shift exhibited a greater number of perseverative responses. An ANOVA indicated that the difference in perseverative trials among the groups was significant $\left(F_{(2,15)}=6.85 ; p<0.01\right)$. Newman-Keuls tests revealed that the tetracaine group had significantly more perseverative trials compared with those in the control groups $(p<0.05)$. The difference in perseverative trials between the control groups was not significant $(p>0.05)$.

The results on learning from the same start arm used in the response and place versions indicated that the groups exhibited similar patterns of learning. The difference in trials to criterion among the groups was not statistically significant $\left(F_{(2,15)}=0.41\right.$; $p>0.05)$. Prelimbic-infralimbic inactivation did not affect learning when started from a new arm. An ANOVA revealed that the difference in trials to criterion among the groups was not significant $\left(F_{(2,15)}=0.77 ; p>0.05\right)$. Overall, prelimbic-infralimbic inactivation did not impair learning on the shift to the place version.

\section{Experiment 3: effect of prelimbic-infralimbic inactivation on a place intramodal shift}

The results on place acquisition and reversal learning are shown in Figure $5 A$. Because in Experiment 1 tetracaine infusions did not affect acquisition of the place discrimination, there was no tetracaine group included on acquisition. A $t$ test revealed that there was no significant difference in reaching trials to criterion on acquisition between the vehicle-injected groups $\left(t_{(8)}=0.81\right.$; $p>0.05)$. On the first session of the place intramodal shift, vehicle- and tetracaine-injected rats performed in a comparable manner, with mean scores of $53.0 \pm 3.4$ and $46.0 \pm 5.1$, respectively. The analysis on the place intramodal shift indicated that the difference in trials to criterion between the control and tetracaine groups was not significant $\left(t_{(8)}=1.46 ; p>0.05\right)$.

Although prelimbic-infralimbic inactivation did not impair an intramodal shift of the place discrimination, it is possible that tetracaine infusions still modified perseveration and learning on the shift. For example, tetracaine infusions may have increased perseveration and facilitated learning or impaired learning and decreased perseveration without producing an overall change on trials to criterion. Thus, an analysis of perseveration and learning on the intramodal shift was performed. Figure $5 B$ shows the perseveration and learning results on the place intramodal shift. Prelimbic-infralimbic inactivation did not affect perseveration or learning during the place intramodal shift. Student's $t$ tests indicated that the differences in the scores between the groups on perseveration and learning were not significant $\left(_{(8)}=0.30\right.$ and $0.88 ; p>0.05$, respectively).

\section{Experiment 4: effect of prelimbic-infralimbic inactivation on a response intramodal shift}

Figure $6 A$ illustrates the results on response acquisition and response reversal learning. Because prelimbic-infralimbic inactivation did not impair acquisition of response learning in Experiment 2, there was no tetracaine group included on acquisition of the response discrimination. A $t$ test on the results from response acquisition indicated that there was not a significant difference in trials to criterion between the vehicle-injected groups $\left(t_{(8)}=0.29\right.$; $p>0.05)$. Vehicle- and tetracaine-injected rats performed comparably on the first session of the response intramodal shift, with mean scores of $31.0 \pm 2.9$ and $35.0 \pm 7.7$, respectively. A $t$ test revealed that the difference in reaching trials to criterion between the groups was not significant $\left(t_{(8)}=0.11 ; p>0.05\right)$. 
A

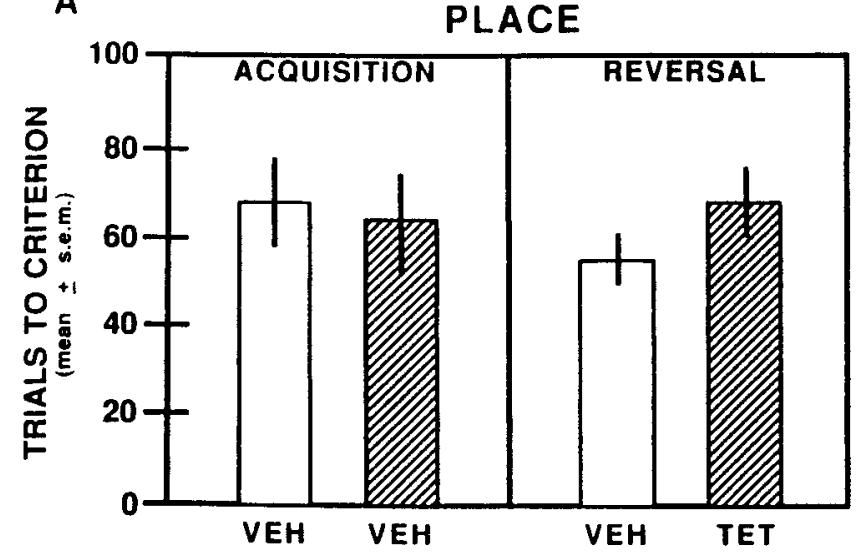

B

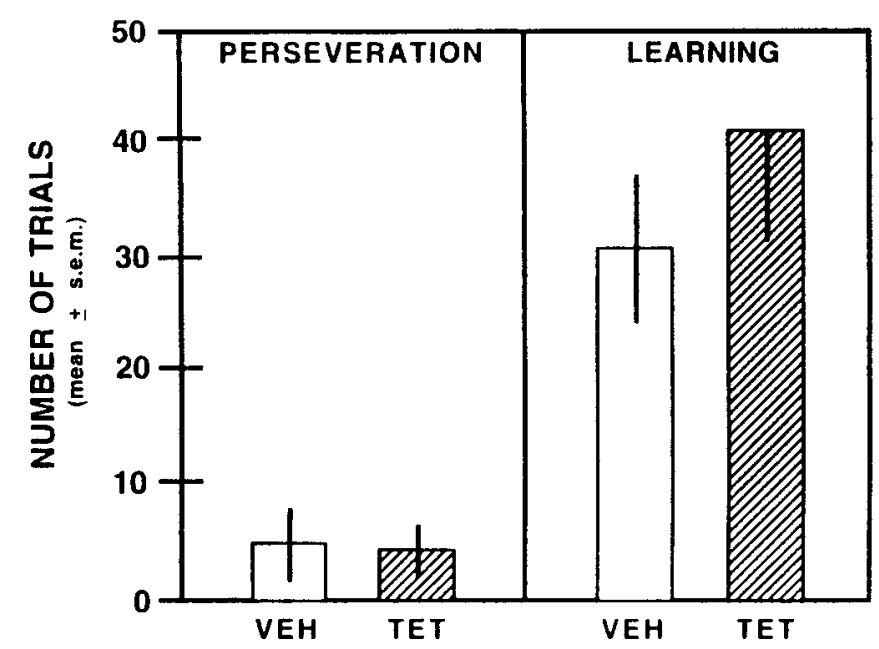

Figure 5. A, Mean trials to criterion on acquisition and reversal of the place discrimination after vehicle or $2 \%$ tetracaine infusions into the prelimbic-infralimbic areas. $V E H$, Saline; TET, $2 \%$ tetracaine. B, Mean number of trials to perseverate and complete learning on reversal of the place discrimination after vehicle or $2 \%$ tetracaine infusions into the prelimbic-infralimbic areas.

As with the place intramodal shift, a further analysis examined perseveration and learning on the response intramodal shift. The results are illustrated in Figure $6 B$. The control and tetracaine groups showed similar amounts of perseveration, as revealed by a $t$ test indicating that there was not a significant difference in perseverative scores between the groups $\left(t_{(8)}=0.63 ; p>0.05\right)$. Furthermore, vehicle- and tetracaine-injected rats had comparable rates of learning, as indicated by a $t$ test that revealed that the difference in learning scores between the groups was not significant $\left(t_{(8)}=1.36 ; p>0.05\right)$.

\section{Experiment 5: effect of prelimbic-infralimbic inactivation on place learning when shifted to a novel environment}

The effects of switching rats to a novel context for the place discrimination are shown in Figure 7. In the novel environment, there was no difference in performance between rats that were tested on the place intramodal shift compared with those that were tested on the place cross-modal shift. Furthermore, the scores in the novel environment were comparable between rats

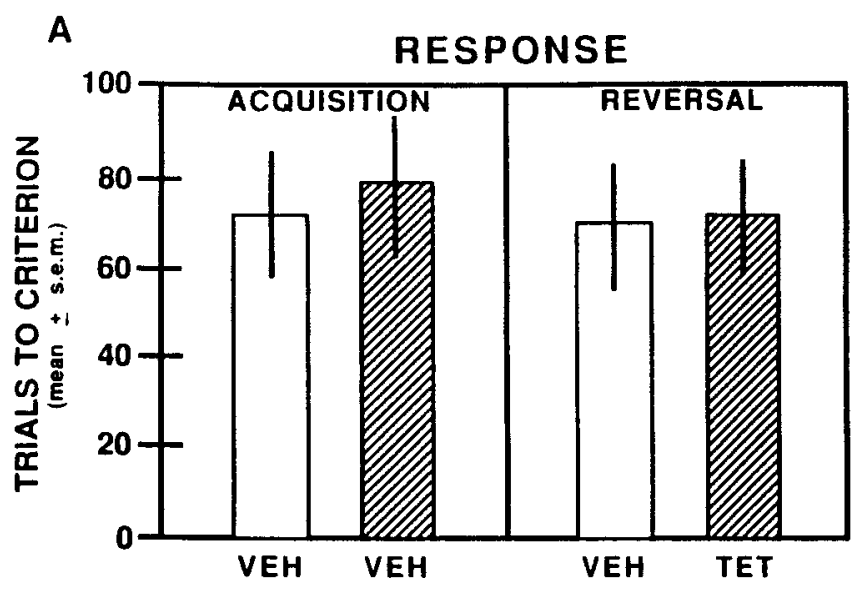

B

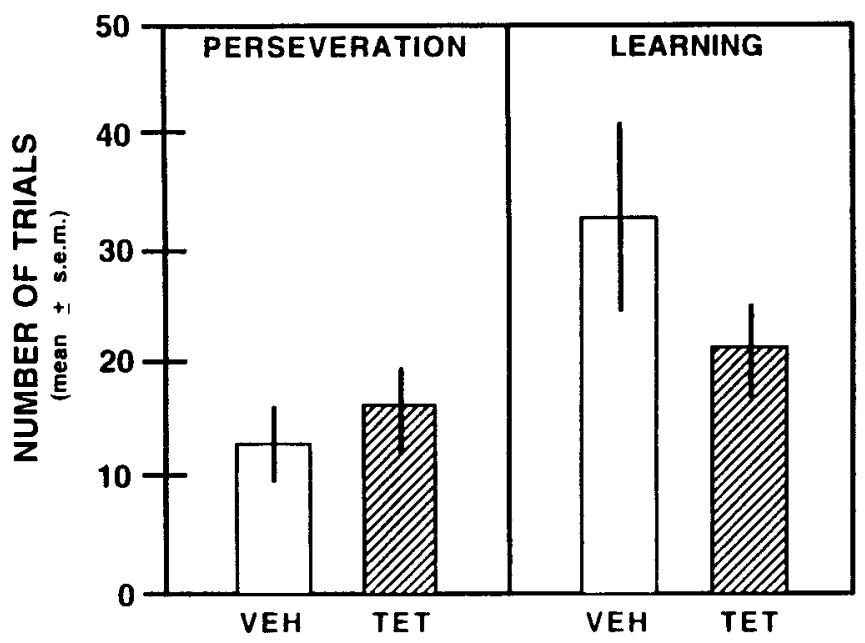

Figure 6. A, Mean trials to criterion on acquisition and reversal of the response discrimination after vehicle or $2 \%$ tetracaine inf usions into the prelimbic-infralimbic areas. $V E H$, Saline; TET, $2 \%$ tetracaine. $B$, Mean number of trials to perseverate and complete learning on reversal of the response discrimination after vehicle or $2 \%$ tetracaine infusions into the prelimbic-infralimbic areas.

that received vehicle injections in the first room compared with those that received tetracaine injections in the first room. The vehicle- and tetracaine-injected groups dropped their scores from $\sim 85$ to $65 \%$ correct when shifted to a new room. The drop in performance was not attributable to a predominance of errors from the new start arm [the mean percent of total errors made from the new start arm was $37.0 \pm 3.7 \%$ (SEM)]. On subsequent test sessions, the groups showed a similar pattern of learning, with scores $>80 \%$ correct by the third session. A two-way ANOVA with repeated measures indicated that there was not a significant difference in the scores between the groups $\left(F_{(1,9)}=0.003 ; p>\right.$ $0.05)$. There was a significant effect for session $\left(F_{(3,27)}=12.86\right.$; $p<0.01)$. Newman-Keuls tests indicated that scores on the first session in the new room were significantly lower than those from the last session in the old room and the third session in the new room $(p<0.05)$. There was not a significant difference in the scores between the last session in the old room and the second or third session in the new room $(p>0.05)$. In addition, there was not a significant group $\times$ session interaction $\left(F_{(3,27)}=0.53 ; p>0.5\right)$. 


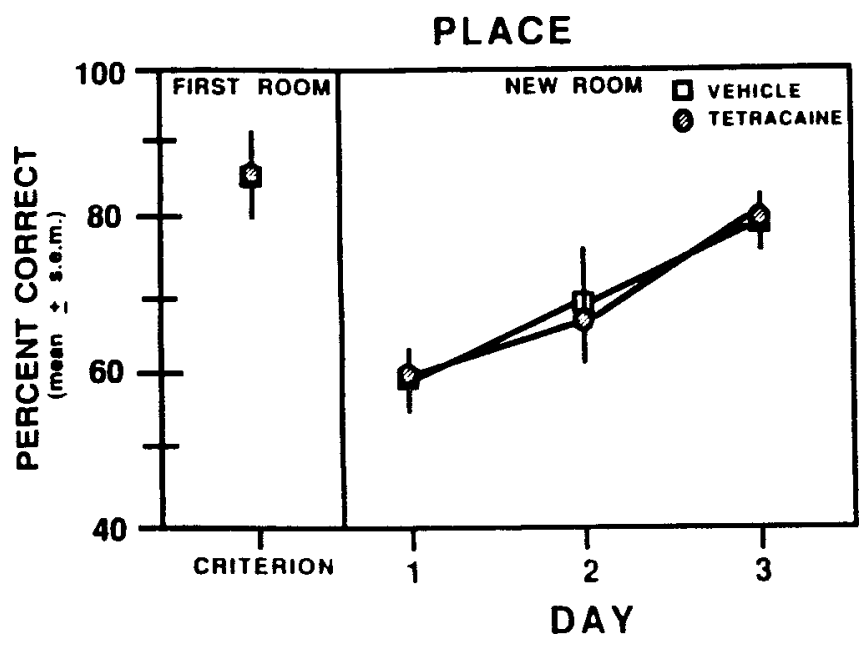

Figure 7. Mean percent correct in the place discrimination during the last test session in the first room and the subsequent three test sessions that occurred in a new room after vehicle or $2 \%$ tetracaine injections into the prelimbic-infralimbic areas. Symbols representing the FIRST ROOM data: $\square$, vehicle or $2 \%$ tetracaine; vehicle.

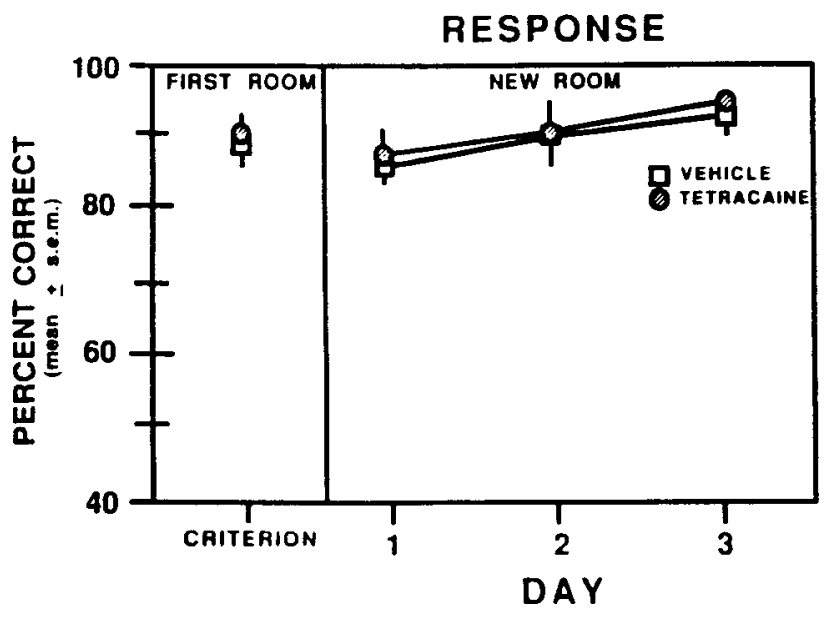

Figure 8. Mean percent correct in the response discrimination during the last test session in the first room and the subsequent three test sessions that occurred in a new room after vehicle or $2 \%$ tetracaine injections into the prelimbic-infralimbic areas. Symbols representing the FIRST ROOM data: $\square$, vehicle or $2 \%$ tetracaine; 0 , vehicle.

\section{Experiment 6: effect of prelimbic-infralimbic inactivation on response learning when shifted to a novel environment}

The findings on response learning in a new room are shown in Figure 8. In the novel environment, there was no difference in performance between rats that were tested on the response intramodal shift compared with those that were tested on the response cross-modal shift. Furthermore, the scores in the novel environment were comparable between rats that received vehicle injections in the first room and those that received tetracaine injections in the first room. During the last session in the first room rats averaged $>85 \%$ correct on the response discrimination. When shifted to the new room, vehicle- and tetracaineinjected rats performed similarly, as on the last session in the first room. However, both groups continued to improve their performance across sessions, with each group reaching $\sim 95 \%$ correct by the third session. A two-way ANOVA with repeated measures indicated that there was not a significant difference in scores between the groups $\left(F_{(1,10)}=1.07 ; p>0.05\right)$. There was a significant effect for session $\left(F_{(3,30)}=3.02 ; p<0.05\right)$, reflecting an improvement in response learning across sessions in the new room. There was not a significant group $\times$ session interaction $\left(F_{(3,30)}=0.12 ; p>0.05\right)$.

\section{DISCUSSION}

The findings from Experiments 1 and 2 indicate that prelimbicinfralimbic inactivation impaired cross-modal shifting when rats were switched from a place to a response discrimination and vice versa. These findings extend previous results indicating that prelimbic-infralimbic inactivation or prelimbic-infralimbic lesions cause a deficit in shifting between place and visual cued discriminations (deBruin et al., 1994; Ragozzino et al., 1999). This raises the possibility that the prelimbic-infralimbic areas play a general role in behavioral flexibility for cross-modal shifts. However, the role of the prelimbic-infralimbic areas in behavioral flexibility may not be limited to shifts between different attributes or sensory-based dimensions. For example, prelimbic-infralimbic lesions impair shifting from a nonmatch-to-position to match-toposition rule in an operant chamber (Joel et al., 1997a) and prelimbic inactivation impairs switching to a different foraging strategy in an eight-arm radial maze (Seamans et al., 1995). In these experiments the attribute or stimulus dimension remained the same, but the rule changed. These results suggest that the prelimbic-infralimbic areas may also be involved in the learning and flexible use of higher-order rules in which behavior cannot be guided simply by applying a valence to a place, turn response, or object (Wise et al., 1996).

An examination of the deficit in cross-modal shifts indicates that prelimbic-infralimbic inactivation caused perseveration of the previous strategy but did not impair learning. These findings are consistent with previous studies showing that humans with frontal lobe damage are impaired in shifting away from a dimension or rule that was previously correct (Milner, 1964; Owen et al., 1993). The findings on the cross-modal tests also revealed that the impairments after prelimbic-infralimbic inactivation were selective to shifting strategies, because there was no deficit in acquiring the place or response discrimination. These results are comparable with previous experiments demonstrating that medial prefrontal lesions centered in the prelimbic-infralimbic areas do not impair learning of place or position discriminations (deBruin et al., 1994; Aggleton et al., 1995; Granon and Poucet, 1995; Delatour and Gisquet-Verrier, 1996). Evidence from other experiments suggest that the striatum may be important for learning and/or the expression of egocentric response discriminations, whereas the hippocampal formation may be important for learning and/or expression of place discriminations (Potegal, 1969; DeCastro, 1974; Morris et al., 1982; Cook and Kesner, 1988; Packard and McGaugh, 1996). Thus, the prelimbic-infralimbic areas may be part of a neural system that is important when one discrimination rule must be inhibited and a new discrimination rule must be learned involving a different attribute but is not critical for acquiring a place or response discrimination.

Previous findings indicate that with extensive training rats frequently shift from using a place strategy to using a response strategy (Hicks, 1964; Packard and McGaugh, 1996). Thus, it is possible that at the end of place discrimination testing rats were actually using a response strategy to solve the task. However, the results on the shift to the novel environment did not support this idea. Rats that completed place discrimination testing and then 
were tested on the place version in a novel environment initially had a significant drop in performance. These results are consistent with the idea that rats use extramaze cues to solve the place discrimination. This result may differ from previous findings that showed a shift from a place to a response strategy because of procedural differences. In particular, previous experiments that demonstrated a shift in place-response learning used only one start arm such that a rat always made the same motor response to receive a reinforcement. In the present experiments on the place discrimination, two start arms were used in which a rat had to make two different motor responses, e.g., navigate straight and turn left, and thus may have decreased the use of an egocentric response strategy. In contrast to the findings on the place discrimination in the new room, rats that finished on the response version and then were tested on this version in a novel environment did not have a drop in performance. These findings suggest that rats were using an egocentric response strategy, but not a spatial strategy, to solve the response discrimination. Furthermore, prelimbic-infralimbic inactivation did not affect performance on the place or response discrimination in the novel environment. Thus, after a discrimination strategy or rule is learned, the prelimbic-infralimbic areas may not be important for the expression of that strategy in a new context.

Although prelimbic-infralimbic inactivation did not impair acquisition of place or response learning, it did significantly increase the scores in reaching trials to criterion compared with acquisition criterion on the place discrimination. This was because tetracaine-injected rats on place acquisition made more errors on the probe trials. However, this effect was only observed on acquisition of the place discrimination and not when rats were shifted to the place version from the response version or during the place intramodal shift. In a strict sense, the increase in probe trials on place acquisition was not attributable to novelty, because the tetracaine group took more than four probe trials on average before getting one correct. Granon and Poucet (1995) reported that increasing the start locations in the Morris water maze impairs the ability of medial prefrontal lesioned rats to navigate to a hidden platform. This deficit was interpreted as an inability to plan accurate trajectories to the goal platform (Granon and Poucet, 1995). This raises the possibility that prelimbic-infralimbic inactivation impairs performance on the place probe trials because of increased task demands leading to a deficit in planning new spatial trajectories. However, this impairment may be limited to conditions in which there is increased task demands on acquisition of a allocentric spatial task with no previous testing in the same context.

The findings from Experiments 3 and 4 indicate that the prelimbic-infralimbic areas are not important for place or response intramodal shifts. These findings are consistent with previous results indicating that medial prefrontal lesions that include the prelimbic-infralimbic areas did not impair place intramodal shifts (deBruin et al., 1994; Granon and Poucet, 1995; Joel et al., $1997 b)$ or reversal of a position response in an operant task (Aggleton et al., 1995). The place intramodal shift in the present study was only between two arms compared with that of Joel and colleagues (1997b), who tested an intramodal shift in an eight-arm radial maze using a four-arm baited and four-arm unbaited procedure. However, even in this task, which had a greater mnemonic load, prelimbic lesions did not cause a deficit in the intramodal shift. Overall, the results from Experiments 1-4 indicate that the prelimbic-infralimbic areas are involved in particular types of behavioral flexibility. The selective involvement of the prelimbic-infralimbic areas in cross-modal but not intramodal shifts is comparable with findings in nonhuman primates, indicating that the dorsolateral prefrontal cortex is involved in cross-modal but not intramodal shifts (Dias et al., 1996, 1997). Moreover, the present results support the view that different prefrontal cortex subregions contribute to different types of rule learning (Wise et al., 1996).

Although the prefrontal cortex may play a role in rule learning, there is considerable evidence indicating the importance of the prefrontal cortex in working memory (Brito et al., 1982; Goldman-Rakic, 1987; Seamans et al., 1995; Kesner et al., 1996; Cohen et al., 1997; Courtney et al., 1997; Ragozzino et al., 1998). Some working memory theories propose that cognitive flexibility deficits on the Wisconsin Card Sorting Task and Stroop Task reflect working memory impairments (Goldman-Rakic, 1987; Kimberg et al., 1997). For example, the Wisconsin Card Sorting Task may activate short-term memory for storage of feedback on sorting choices for use on subsequent trials (Kimberg et al., 1997). Based on these theories, one possibility is that the behavioral flexibility deficits observed in the present experiments may be interpreted as working memory impairments. However, the present results do not appear to support this hypothesis. In particular, if the cross-modal shifting impairments reflect a deficit in the short-term storage of feedback from arm choices, then a deficit should also occur on the intramodal shifts after prelimbicinfralimbic inactivation. In contrast to this hypothesis, prelimbicinfralimbic inactivation did not even produce a transient deficit on the intramodal shifts, because controls and tetracaine-injected rats exhibit similar scores on the first reversal session for both place and response intramodal shifts. Moreover, although these intramodal shifts may be less difficult than the cross-modal shifts, as noted above, prelimbic-infralimbic lesions do not impair intramodal shifts even when task demands are increased (Joel et al., 1997b). Thus, the deficits in cross-modal shifts produced by prelimbic-infralimbic inactivation more likely reflect inhibitory deficits related to shifting strategies (Dias et al., 1997) as opposed to impairments in working memory processes (Goldman-Rakic, 1987; Kimberg et al., 1997).

\section{REFERENCES}

Aggleton JP, Neave N, Nagle S, Sahgal A (1995) A comparison of the effects of medial prefrontal, cingulate cortex and cingulum bundle lesions on tests of spatial memory: evidence of a double dissociation between frontal and cingulum bundle contributions. J Neurosci 15:7270-7281.

Becker JT, Olton DS (1980) Object discrimination by rats: the role of frontal and hippocampal systems in retention and reversal. Physiol Behav 24:33-38.

Becker JT, Olton DS, Anderson CA, Breitinger ERP (1981) Cognitive mapping in rats: the role of the hippocampal and frontal systems in retention and reversal. Behav Brain Res 3:1-22.

Brito GNO, Thomas GJ, Davis BJ, Gingold SI (1982) Prelimbic cortex, mediodorsal thalamus, septum and delayed alternation in rats. Exp Brain Res 46:52-58.

Bussey TJ, Muir JL, Everitt BJ, Robbins TW (1997) Triple dissociation of anterior cingulate, posterior cingulate, and medial prefrontal cortices on visual discrimination using a touchscreen testing procedure for the rat. Behav Neurosci 111:920-936.

Cohen JD, Perlstein WM, Braver TS, Nystrom LE, Noll DC, Jonides J, Smith EE (1997) Temporal dynamics of brain activation during a working memory task. Nature 386:604-607.

Cook D, Kesner RP (1988) Caudate nucleus and memory for egocentric localization. Behav Neural Biol 49:332-343.

Courtney SM, Ungerleider LG, Kell K, Haxby JV (1997) Transient and sustained activity in a distributed neural system for human working memory. Nature 386:608-611.

deBruin JPC, Sanchez-Santed F, Heinsbroek RPW, Donker A, Postmes P 
(1994) A behavioural analysis of rats with damage to the medial prefrontal cortex using the Morris water maze: evidence for behavioral flexibility, but not for impaired navigation. Brain Res 652:323-333.

DeCastro JM (1974) A selective spatial discrimination deficit after fornicotomy in the rat. Behav Biol 12:373-382.

DeCoteau WE, Kesner RP, Williams JM (1997) Short-term memory for food reward magnitude: the role of the prefrontal cortex. Behav Brain Res 88:239-249.

Delatour B, Gisquet-Verrier P (1996) Prelimbic cortex specific lesions disrupt delayed-variable response tasks in the rat. Behav Neurosci 110:1282-1298.

Dias R, Robbins TW, Roberts AC (1996) Dissociation in prefrontal cortex of affective and attentional shifts. Nature 380:69-72.

Dias R, Robbins TW, Roberts AC (1997) Dissociable forms of inhibitory control within prefrontal cortex with an analog of the Wisconsin Card Sorting Test: restriction to novel situations and independence from "on-line" information. J Neurosci 17:9265-9297.

Eichenbaum H, Clegg RA, Feeley A (1983) Reexamination of functional subdivisions of the rodent prefrontal cortex. Exp Neurol 79:434-451.

Givens BS, Olton DS (1990) Cholinergic and GABAergic modulation of medial septal area: effect on working memory. Behav Neurosci 104:849-855.

Goldman-Rakic PS (1987) Circuitry of primate prefrontal cortex and regulation of behavior by representational memory. In: Handbook of physiology, Vol 5, The nervous system (Plum F, Mountcastle V, eds), pp 373-417. Bethesda, MD: American Physiological Society.

Granon S, Poucet B (1995) Medial prefrontal lesions in the rat and spatial navigation: evidence for impaired planning. Behav Neurosci 108:883-891.

Hicks LH (1964) Effects of overtraining on acquisition and reversal of place and response learning. Psychol Rep 15:459-462.

Hunt PR, Aggleton JP (1998) Neurotoxic lesions of the dorsomedial thalamus impair the acquisition but not the performance of delayed matching to place by rats: a deficit in shifting response rules. J Neurosci 18:10045-10052.

Jeeves MA (1967) Some paradoxical effects of bilateral lesions in the frontal cortex in rats. Neuropsychologia 5:73-84.

Joel D, Weiner I, Feldon J (1997a) Electrolytic lesions of the medial prefrontal cortex in rats disrupt performance on an analog of the Wisconsin Card Sorting Test, but do not disrupt latent inhibition: implications for animal models of schizophrenia. Behav Brain Res 85:187-201.

Joel D, Tarrasch R, Feldon J, Weiner I (1997b) Effects of electrolytic lesions of the medial prefrontal cortex or its subfields on 4-arm baited, 8 -arm radial maze, two-way active avoidance and conditioned fear tasks in the rat. Brain Res 765:37-50.

Kesner RP, Farnsworth G, DiMattia BV (1989) Double dissociation of egocentric and allocentric space following medial prefrontal and parietal cortex lesions in the rat. Behav Neurosci 103:38-43.

Kesner RP, Hunt ME, Williams JM, Long JM (1996) Prefrontal cortex and working memory for spatial response, spatial location and visual object information in the rat. Cereb Cortex 6:311-318.

Kimberg DY, D'Esposito M, Farah MJ (1997) Cognitive functions in the prefrontal cortex-working memory and executive control. Curr Dir Psychol Sci 6:185-192.

Kolb B (1990) Animal model for human PFC-related disorders. Prog Brain Res 85:501-519.
Kolb B, Nonneman AJ, Singh RK (1974) Double dissociation of spatial impairments and perseveration following selective prefrontal lesions in rats. J Comp Physiol Psychol 87:772-780.

Kolb B, Sutherland RJ, Whishaw IQ (1983) A comparison of the contributions of the frontal and parietal association cortex to spatial localization in rats. Behav Neurosci 97:13-27.

Milner B (1964) Some effects of frontal lobectomy in man. In: The frontal granular cortex and behavior (Warren JM, Akert K, eds), pp 313-334. New York: McGraw-Hill.

Mizumori SJY, McNaughton BL, Barnes CA, Fox KB (1989) Preserved spatial coding in hippocampal CA1 pyramidal cells during reversible suppression of CA3 output: evidence for pattern completion in hippocampus. J Neurosci 9:3915-3928.

Mizumori SJY, Perez GM, Alvarado MC, Barnes CA, McNaughton BL (1990) Reversible inactivation of the medial septum differentially affects two forms of learning in rats. Brain Res 328:12-20.

Morris RGM, Garrund P, Rawlins JNP, O'Keefe J (1982) Place navigation impaired in rats with hippocampal lesions. Nature 297:681-683.

Nonneman AJ, Voigt J, Kolb B (1974) Comparisons of behavioral effects of hippocampal and prefrontal cortex lesions in the rat. J Comp Physiol Psychol 87:249-260.

Owen AM, Downes JJ, Sahakian BJ, Evenden J, Heald A, Robbins TW (1990) Planning and spatial working memory following frontal lobe lesions in man. Neuropsychologia 28:1021-1034.

Owen AM, Roberts AC, Hodges JR, Summers BA, Polkey CE, Robbins TW (1993) Contrasting mechanisms of impaired attentional setshifting in patients with frontal lobe damage or Parkinson's disease. Brain 116:1159-1175.

Packard MG, McGaugh JL (1996) Inactivation of hippocampus or caudate nucleus with lidocaine differentially affects expression of place and response learning. Neurobiol Learn Mem 65:65-72.

Paxinos G, Watson C (1986) The rat brain in stereotaxic coordinates, Ed 2. Sydney, Australia: Academic.

Potegal M (1969) Role of the caudate nucleus in spatial orientation of rats. J Comp Physiol Psychol 69:756-764.

Ragozzino ME, Adams S, Kesner RP (1998) Differential involvement of the dorsal anterior cingulate and prelimbic-infralimbic areas of the rodent prefrontal cortex in spatial working memory. Behav Neurosci 112:233-243.

Ragozzino ME, Wilcox C, Raso M, Kesner RP (1999) Involvement of rodent prefrontal cortex subregions in strategy switching. Behav Neurosci 113:32-41.

Seamans JK, Floresco SB, Phillips AG (1995) Functional differences between the prelimbic and anterior cingulate regions of the rat prefrontal cortex. Behav Neurosci 109:1063-1073.

Thompson WG, Guilford MO, Hicks LH (1980) Effects of caudate and cortical lesions on place and response learning in rats. Physiol Psychol $8: 473-479$

Thomsen W, Hays SJ, Hicks JL, Schwarz RD, Catterall WA (1993) Specific binding of the novel $\mathrm{Na}+$ channel blocker PD85,639 to the alpha subunit of rat brain $\mathrm{Na}+$ channels. Mol Pharmacol 43:955-964.

Velly J, Grima M, Decker N, Cragoe EJ, Schwartz J (1988) Effects of amiloride and its analogues on 3 H-batrachotoxinin-A 20 -alpha benzoate binding, $3 \mathrm{H}$-tetracaine binding and $22 \mathrm{Na}$ influx. Eur J Pharmacol 149:97-105.

Wise SP, Murray EA, Gerfen CR (1996) The frontal cortex-basal ganglia system in primates. Crit Rev Neurobiol 10:317-356. 